\title{
The median isn't the message
}

My life has recently intersected, in a most personal way, two of Mark Twain's famous quips. One I shall defer to the end of this essay. The other (sometimes attributed to Disraeli), identifies three species of mendacity, each worse than the one before - lies, damned lies, and statistics.

Consider the standard example of stretching the truth with numbers - a case quite relevant to my story. Statistics recognises different measures of an "average", or central tendency. The mean is our usual concept of an overall average - add up the items and divide them by the number of sharers (100 candy bars collected for five kids next Halloween will yield 20 for each in a just world). The median, a different measure of central tendency, is the half-way point. If I line up five kids by height, the median child is shorter than two and taller than the other two (who might have trouble getting their mean share of the candy). A politician in power might say with pride, "The mean income of our citizens is $\$ 15,000$ per year." The leader of the opposition might retort, "But half our citizens make less than $\$ 10000$ per year." Both are right, but neither cites a statistic with impassive objectivity. The first invokes a mean, the second a median. (Mean is higher than median in such cases because one millionaire may outweigh hundreds of poor people in setting a mean; but he can balance only one mendicant in calculating a median).

The larger issue that creates a common distrust or contempt for statistics is more troubling. Many people make an unfortunate and invalid separation between heart and mind, or feeling and intellect. In some contemporary traditions, abetted by attitudes stereotypically centered on Southern California, feelings are exalted as more "real" and the only proper basis for action - if it feels good, do it - while intellect gets short shrift as a hang-up of outmoded elitism. Statistics, in this absurd dichotomy, often becomes the symbol of the enemy. As Hilaire Belloc wrote, "Statistics are the triumph of the quantitative method, and the quantitative method is the victory of sterility and death."

This is a personal story of statistics, properly interpreted, as profoundly nurturant and life-giving. It declares holy war on the downgrading of intellect by telling a small story about the utility of dry, academic knowledge about science. Heart and head are focal points of one body, one personality.

In July 1982, I learned that I was suffering from abdominal mesothelioma, a rare and serious cancer usually associated with exposure to asbestos. When I revived after surgery, I asked my first question of my doctor and chemotherapist, "What is the best technical literature about mesothelioma?" She replied, with a touch of diplomacy (the only departure she has ever made from direct frankness), that the medical literature contained nothing really worth reading.

Of course, trying to keep an intellectual away from literary works about as well as recommending chastity to
Homo sapiens, the sexiest primate of all. As soon as I could walk, I made a beeline for Harvard's Countway medical library and punched mesothelioma into the computer's bibliographic search program. An hour later, surrounded by the latest literature on abdominal mesothelioma, I realised with a gulp why my doctor had offered that humane advice. The literature couldn't have been more brutally clear: mesothelioma is incurable, with a median mortality of only eight months after discovery. I sat stunned for about $15 \mathrm{~min}$, then smiled and said to myself, so that's why they didn't give me anything to read. Then my mind started to work again, thank goodness.

If a little learning could ever be a dangerous thing, I had encountered a classic example. Attitude clearly matters in fighting cancer. We don't know why (from my old-style materialistic perspective, I suspect that mental states feed back upon the immune system). But match people with the same cancer for age, class, health, socioeconomic status, and, in general, those with positive attitude, with a strong will and purpose for living, with commitment to struggle, with an active response to aiding their own treatment and not just a passive acceptance of anything doctors say, tend to live longer. A few months later I asked Sir Peter Medawar, my personal scientific guru and a Nobelist in immunology, what the best prescription for success against cancer might be. "A sanguine personality", he replied. Fortunately (since one can't reconstruct oneself at short notice and for a definite purpose), I am, if anything, even-tempered and confident in just this manner.

Hence the dilemma for humane doctors: since attitude matters so critically, should such a sombre conclusion be advertised, especially since few people have sufficient understanding of statistics to evaluate what the statements really mean? From years of experience with the small-scale evolution of Bahamian land snails treated quantitatively, I have developed this technical knowledge - and I am convinced that it played a major role in saving my life. Knowledge is indeed power, in Bacon's proverb.

The problem may be briefly stated: What does "median mortality of eight months" signify in our vernacular? I suspect that most people, without training in statistics, would read such a statement as "I will probably be dead in eight months" - the very conclusion that must be avoided, since it isn't so, and since attitude matters so much.

I was not, of course, overjoyed, but I didn't read the statement in this vernacular way either. My technical training enjoined a different perspective on "eight months median mortality." The point is a subtle one, but profound - for it embodies the distinctive way of thinking in my own field of evolutionary biology and natural history.

We still carry the historical baggage of a Platonic heritage that seeks sharp essence and definite boundaries. 
(Thus we hope to find an unambiguous "beginning of life" or "definition of death", although nature often comes to us as irreducible continua.) This Platonic heritage, with its emphasis in clear distinctions and separated immutable entities, leads us to view statistical measures of central tendency wrongly, indeed opposite to the appropriate interpretation in our actual world of variation, shadings, and continua. In short, we view mean and median as the hard "realities", and as the variation that permits their calculation as a set of transient and imperfect measurements of this hidden essence. If the median is the reality and variation around the median just a device for its calculation, the "I will probably be dead in eight months" may pass as a reasonable interpretation.

But all evolutionary biologists know that variation itself is nature's only irreducible essence. Variation is the hard reality, not a set of imperfect measures for a central tendency. Mean and median are the abstractions. Therefore, I looked at the mesothelioma statistics quite differentlyand not only because I am an optimist who tends to see the doughnut instead of the hole, but primarily because I know that variation itself is the reality. I had to place myself amidst the variation.

When I learned about the 8-month median, my first intellectual reaction was: fine, half the people will live longer; now what are my chances of being in that half. I read for a furious and nervous hour and concluded, with relief: damned good. I possessed every one of the characteristics conferring a probability of longer life-I was young; my disease had been recognised in a relatively early stage; I would receive the nation's best medical treatment; I had the world to live for; I knew how to read the data properly and not despair.

Another technical point then added even more solace. I immediately recognised that the distribution of variation about the 8 -month median would almost surely be what statisticians call "right skewed". (In a symmetrical distribution, the profile of variation to the left of the central tendency is a mirror image of variation to the right. In skewed distributions, variation to one side of the central tendency is more stretched out-left skewed if extended to the left, right skewed if stretched out to the right.) The distribution of variation had to be right skewed, I reasoned. After all, the left of the distribution contains an irrevocable lower boundary of zero (since mesothelioma can only be identified at death or before). Thus, there isn't much room for the distribution's lower (or left) half - it must be scrunched up between 0 and 8 months. But the upper (or right) half can extend out for years and years, even if nobody ultimately survives. The distribution must be right skewed, and I needed to know how long the extended tail ran-for I had already concluded that my favourable profile made me a good candidate for that part of the curve.

The distribution was indeed, strongly right skewed, with a long tail (however small) that extended for several years above the 8-month median. I saw no reason why I shouldn't be in that small tail, and I breathed a very long sigh of relief. My technical knowledge had helped. I had read the graph correctly. I had asked the right question and found the answers. I had obtained, in all probability, the most precious of all possible gifts in the circumstances - substantial time. I didn't have to stop and immediately follow Isaiah's injunction to Hezekiah - set thine house in order for thou shalt die, and not live. I would have time to think, to plan, and to fight.

One final point about statistical distributions. They apply only to a prescribed set of circumstances - in this case to survival with mesothelioma under conventional modes of treatment. If circumstances change, the distribution may alter. I was placed on an experimental protocol of treatment and, if fortune holds, will be in the first cohort of a new distribution with high median and a right tail extending to death by natural causes at advanced old age.

It has become, in my view, a bit too trendy to regard the acceptance of death as something tantamount to intrinsic dignity. Of course I agree with the preacher of Ecclesiastes that there is a time to love and a time to dieand when my skein runs out I hope to face the end calmly and in my own way. For most situations, however, I prefer the more martial view that death is the ultimate enemyand I find nothing reproachable in those who rage mightily against the dying of the light.

The swords of battle are numerous, and none more effective than humour. My death was announced at a meeting of my colleagues in Scotland, and I almost experienced the delicious pleasure of reading my obituary penned by one of my best friends (the so-and-so got suspicious and checked; he too is a statistician, and didn't expect to find me so far out on the right tail). Still, the incident provided my first good laugh after the diagnosis. Just think, I almost got to repeat Mark Twain's most famous line of all: the reports of my death are greatly exaggerated.

SJ Gould, concerguide.org / median_not_msg.html @stephenjaygould.

Editor's note: Stephen Jay Gould is the author of at least 10 popular books on evolution, including The Flamingo's Smile, The Mismeasure of Man, Wonderful Life and Full Hours. He lived for 20 highly productive years after the initial diagnosis of mesothelioma, exceeding the 8 month median survival for that cancer by a factor of 30 ! He died of a different cancer at the age of 60, in May 2002, having completed his 1342 page "Magnum Opus" titled, The Structure of Evolutionary Theory a few months before death. CG 